\title{
DEPRESSION AMONG 43-55 YEAR OLD WOMEN IN A RURAL AREA IN KERALA.
}

S. Anil Bindhu¹.

1. Associate Professor, Department of Community Medicine, Sree Gokulam Medical College \& RF, Trivandrum.

\section{CORRESPONDING AUTHOR}

\section{Dr. S. Anil Bindhu,}

Krishnagiri,Venpalavattom,

Anayara.P.O. Thiruvananthapuram,

Kerala- 695029.

Email-dranilbindu@gmail.com

\section{HOW TO CITE THIS ARTICLE:}

Anil Bindhu. "Depression among 43-55 year old women in a rural area in Kerala". Journal of Evolution of Medical and Dental Sciences 2013; Vol2, Issue 24, June 17; Page: 4380-4386.

Menopause is a transitional period that woman goes through if she lives beyond the age of 55 years. Menopause is characterized by physiologic and psychosocial changes in a woman's life. Though many depressive symptoms are seen during menopausal transition, the relation of depression with menopausal status is controversial.

OBJECTIVES: To compare the depression among postmenopausal women and women who has not attained menopause in the age group of 43 to 55 years in a rural area in Kerala using Beck's Depression Inventory.

- To find out whether depression is associated with climacteric symptoms among rural women in the age group of 43 to 55 years.

METHODS AND MATERIALS: A cross sectional study was conducted among women in the age group of 43 to 55 years in a rural area in Kerala. Data were collected from 320 women by interviewing with the help of a structured questionnaire consisting of a socio-demographic data, Beck's Depression Inventory and the Greene's Climacteric Scale. The SPSS 16.0 was used for statistical analyses. The Chi-square test was applied to find out differences in proportions. Difference in scores for BDI was compared using Mann Whitney U test. Spearman's correlation coefficient was determined to find out the correlation between BDI and GCS scores. P-value less than 0.05 were considered as statistical significant. RESULTS: Mean age of women was $48.96+/-4.04$. The BDI scores among postmenopausal women was significantly higher compared to women who has not attained menopause $(\mathrm{p}<0.001)$. The proportion of women with depression is not significantly higher among postmenopausal women compared to women who has not attained menopause $(p=0.139)$. Moderate/severe depression was significantly higher among women who suffered from any of the vasomotor symptoms, compared to the women who did not suffer from any vasomotor symptoms $(\mathrm{p}<0.001$, OR 6.154(2.235-16.941)). The BDI scores among these women had a positive correlation with Total GCS score (0.760). CONCLUSION: Though the depressive symptoms are higher among post menopausal women compared to pre-menopausal women, as such clinical depression is not found to be significantly increased. 


\section{ORIGINAL ARTICLE}

INTRODUCTION: Menopause is a transitional period that woman goes through if she lives beyond the age of 55 years. Menopause is characterized by physiologic and psychosocial changes in a woman's life. Many women experience vasomotor symptoms at or around the time of menopause. Hot flashes and night sweats are considered as predominant menopausal symptoms. The risk of depression also appears to increase in the menopausal transition.1,2,3,4, Whether the reduction in the hormones associated with menopause leads to depression in middle aged women remains controversial. Some Correlational studies report that there is no link between oestrogen concentrations and depression.5,6 Mathews et al reported that natural menopause is a benign event for the majority of middle-aged healthy women. ${ }^{7}$ The changes in the environment and family circumstances of menopausal women can be important trigger mechanisms acting on the increasingly susceptible biochemical and hormonal environment to bring about depression and mood changes. The presence of vasomotor symptoms appears to be associated with a higher prevalence of depressed mood regardless of prior depression..$^{8,9,10}$ In a cohort study, it is reported that hot flashes and depressive symptoms occurred early in the menopausal transition and that the depressive symptoms are more likely to precede hot flashes in women with no previous experience of either symptom. ${ }^{11}$

The relation of depression with menopausal status is studied in many studies from different parts of the world. But limited research data are available regarding depression among women around the menopausal age in Kerala

\section{OBJECTIVES:}

1. To compare the depression among postmenopausal women and women who has not attained menopause in the age group of 43 to 55 years in a rural area in Kerala using Beck's Depression Inventory.

2. To find out whether depression is associated with climacteric symptoms among rural women in the age group of 43 to 55 years.

METHODS AND MATERIAL: A cross sectional study was conducted in a rural area in Kottayam district in Kerala. A Panchayath which is rural in nature is purposively selected. Three wards were randomly selected for study from the selected Panchayath. The approval of institutional ethical committee was obtained. Study population included all married women in the age group of 43 to 55 years who are permanent residents of this Panchyath. A pilot survey done in 50 postmenopausal women in this village showed that the median age at menopause is 49 years. Hence it was decided to set up upper and lower age boundaries of sample population 6 years from the expected median age at menopause.

\section{EXCLUSION CRITERIA:}

1. Women who had undergone surgical menopause

2. Women receiving hormone replacement therapy

3. Women who attained menopause more than five years back.

All Post-menopausal women who met the inclusion criteria from the selected wards were included in the study. Then for every woman who has attained menopause, woman in the same age group (43-55year) who hasn't attained menopause was chosen from the same area. 


\section{ORIGINAL ARTICLE}

Data were collected from women by interviewing with the help of a structured questionnaire consisting of a socio-demographic data, Beck's Depression Inventory and the Greene's Climacteric Scale.

Depression of women among Women is assessed using Beck's Depression Inventory, ${ }^{12,13}$ a widely used, validated instrument for measuring depression. This is a self rated scale, in which individuals rate their own symptoms of depression. It provides a fast, efficient way to assess depression in either a clinical or non-clinical environment. The Beck Depression Inventory (BDI) takes just 5-10 minutes to complete. The test contains 21 items, most of which assess depressive symptoms on a Likert scale of $0-3$. Each item is a list of four statements arranged in increasing severity about a particular symptom of depression. BDI-II total scores have been correlated with scores on other psychological tests. Clinical interpretation of scores is accomplished through criterion-referenced procedures utilizing the following interpretive ranges: 0-13 - minimal depression; 14-19 - mild depression; 20-28 -moderate depression; and 29-63 - severe depression. Higher total scores indicate more severe depressive symptoms.

The Greene's climacteric scale ${ }^{14,15}$ is a validated menopausal symptom scale used routinely in clinical practice and as a research tool, to assess the prevalence and / severity of climacteric symptoms. The Greene Climacteric scale (GCS) scores the severity of 21 symptoms on a scale of 0 to 3 and divides the symptoms into six subscales. The psychological score (11 symptoms), of which Anxiety (6 symptoms), Depression (5 symptoms), The somatic score (7 symptoms), The vasomotor score (2 symptoms) and The sexual score (1 symptom). Higher scores indicate a greater number of symptoms and / or symptom severity.

All women were interviewed in the local language. Respondents were informed the purpose and objectives of the study and an informed consent was obtained. The participants were informed that their inclusion in the study will be voluntary and were given a guarantee of anonymity.

BDI translated in Malayalam Language were given to each individual subject. The women are directed to read each group of statements carefully and then pick out the one statement in each group that best describes the way they have been feeling. For those women, who are illiterate and who could not read, each item is read out and their responses marked by the investigator.

STATISTICAL ANALYSIS: The Statistical Package for the Social Sciences software Version 16.0 was used for statistical analyses. The Chi-square test was applied to find out differences in proportions and difference in scores for BDI was compared using Mann Whitney U test. Spearman's rank correlation coefficient was determined to find out the correlation between BDI and GCS scores. Pvalue less than 0.05 were considered as statistical significant.

RESULTS: The results of data collected from 320 women in the age group of 43to 55 years in a rural area in Kerala gave the following results. Mean age of this sample was $48.96+/-4.04$. There were 160 post menopausal women in the age group of 43to 55 years who met the inclusion criteria. Equal number women who did not attained menopause also included in the study. $57.2 \%$ women are Hindus, $40 \%$ are Christians and $2.8 \%$ are Muslims. Majority of women, 31.9\% are educated up to high school, followed by $29.1 \%$ up to middle school. $22.8 \%$ are educated up to primary school only. $1.3 \%$ of women didn't go to school and they do not know to read or write. Majority of women (64.4 
$\%$ ) in the study sample were living in nuclear Family. $71.6 \%$ of the all study subjects were house wives.

About $87.2 \%$ women in the age group of 43 to 55 years had minimal depression, $5.3 \%$ had mild depression, $6.9 \%$ had moderate depression and $0.6 \%$ had severe depression as measured by Beck's Depression Inventory. 83.8\% postmenopausal women and 90.6\% women who has not attained menopause had minimal depression, $7.5 \%$ of postmenopausal women3.1\% women who has not attained menopause had mild depression, $7.5 \%$ postmenopausal women $6.2 \%$ women who has not attained menopause and had moderate depression, and $1.2 \%$ postmenopausal women had severe depression. The proportion of women with depression is slightly higher among postmenopausal women than women who has not attained menopause. But this difference is not found to be statistically significant with a p value 0.139 .

But the median BDI score among women who has not attained menopause in the age group of 4355years was 4 with inter- quartile range of 6 and median score among post menopausal women was 6 with inter- quartile range of 7. The total BDI scores among postmenopausal women were found to be higher compared to women who has not attained menopause. This difference is found to be statistically significant with $\mathrm{p}$ value $<0.001$ (Mann-Whitney U test).

TABLE NO. 1: Relation between Climacteric symptoms and Depression

\begin{tabular}{|c|c|c|c|c|c|}
\hline Symptoms & Category & $\begin{array}{l}\text { Minimal/mild } \\
\text { Depression }\end{array}$ & $\begin{array}{l}\text { Moderate/severe } \\
\text { Depression }\end{array}$ & Significance & Odds Ratio \\
\hline \multirow[b]{2}{*}{ Menopause } & $\begin{array}{l}\text { Not } \\
\text { Attained }\end{array}$ & $\begin{array}{l}150 \\
93.8 \%\end{array}$ & $\begin{array}{l}10 \\
6.2 \%\end{array}$ & \multirow[b]{2}{*}{0.525} & \multirow[b]{2}{*}{$\begin{array}{l}1.48 \\
(0.619 \\
.3 .341)\end{array}$} \\
\hline & Attained & $\begin{array}{l}146 \\
91.3 \%\end{array}$ & $\begin{array}{c}14 \\
8.8 \%\end{array}$ & & \\
\hline \multirow[b]{2}{*}{ Hot flashes } & Absent & $\begin{array}{l}182 \\
97.3 \%\end{array}$ & $\begin{array}{l}5 \\
2.7 \%\end{array}$ & \multirow[t]{2}{*}{$<0.001$} & \multirow{2}{*}{$\begin{array}{c}6.067 \\
(2.204- \\
16.699) .\end{array}$} \\
\hline & Present & $\begin{array}{l}114 \\
85.7 \%\end{array}$ & $\begin{array}{l}19 \\
14.3 \%\end{array}$ & & \\
\hline \multirow[b]{2}{*}{ Night sweats } & No & $\begin{array}{l}208 \\
96.7 \%\end{array}$ & $\begin{array}{l}7 \\
3.3 \%\end{array}$ & \multirow[b]{2}{*}{$<0.001$} & 5.74 \\
\hline & Yes & $\begin{array}{l}88 \\
83.8 \%\end{array}$ & $\begin{array}{l}17 \\
16.2 \%\end{array}$ & & $\begin{array}{l}(2.3- \\
14.329)\end{array}$ \\
\hline \multirow[b]{2}{*}{$\begin{array}{l}\text { Disturbed } \\
\text { Sleep }\end{array}$} & No & $\begin{array}{l}214 \\
95.5 \% \\
\end{array}$ & $\begin{array}{l}10 \\
4.5 \% \\
\end{array}$ & \multirow[b]{2}{*}{0.002} & \multirow{2}{*}{$\begin{array}{l}3.654 \\
(1.561- \\
8.552)\end{array}$} \\
\hline & Yes & $\begin{array}{l}82 \\
85.4 \%\end{array}$ & $\begin{array}{l}14 \\
14.6 \%\end{array}$ & & \\
\hline \multirow{2}{*}{$\begin{array}{l}\text { Sexual } \\
\text { disinterest }\end{array}$} & No & $\begin{array}{l}158 \\
96.9 \%\end{array}$ & $\begin{array}{l}5 \\
3.1 \% \\
\end{array}$ & \multirow[b]{2}{*}{0.002} & \multirow{2}{*}{$\begin{array}{l}4.351 \\
(1.583- \\
11.960)\end{array}$} \\
\hline & Yes & $\begin{array}{l}138 \\
87.9 \%\end{array}$ & $\begin{array}{l}19 \\
12.1 \%\end{array}$ & & \\
\hline
\end{tabular}




\section{ORIGINAL ARTICLE}

Moderate/severe depression was significantly higher among women who suffered from hot flashes, compared to the women who did not suffer from hot flashes with $\mathrm{p}<0.001$ and odds ratio 6.067 (2.204-16.699). Moderate/severe depression was significantly higher among women who suffered from night sweats, compared to the women who did not suffer from night sweats with $\mathrm{p}<0.001$ and odds ratio 5.74 (2.3-14.329). Moderate/severe depression was significantly higher among women who suffered from any of the vasomotor symptoms (hot flashes/night sweats), compared to the women who did not suffer from any vasomotor symptoms with $\mathrm{p}<0.001$ and odds ratio 6.154 (2.235-16.941). Poor sleep had a significant association with moderate/severe depression with a p value 0.002 and OR 3.654(1.561-8.552). Lack of sexual interest is found to have a significant association with Moderate/severe depression with p 0.002 and Odds ratio 4.351(1.58311.960).

The BDI scores among women in the age group of 43to 55 years had a positive correlation with Total GCS score with Spearman's Correlation coefficient 0.760 . This Correlation is significant at the 0.001 level. The BDI scores also has a positive correlation with sexual subscale score of GCS with Spearman's Correlation coefficient 0.540 . This Correlation is significant at the 0.001 level.

DISCUSSION: The total BDI scores among postmenopausal women were significantly higher compared to women who has not attained menopause. But it is seen that even though the depressive symptom are higher among post menopausal women compared to pre-menopausal women, as such clinical depression is not found to be significantly increased. In another study also, BDI scores were significantly higher in menopausal women. ${ }^{16}$ In one study, Comparing the postmenopausal period with the peri-menopausal period, the score for depressive symptoms was somewhat higher while the score for anxious symptoms was somewhat lower. These differences did not reach significance. ${ }^{17}$ Two longitudinal, cohort studies that prospectively tracked initially premenopausal women for 5 to 8 years as they transitioned through menopause 3,18,19 documented an increase in risk for the development of depressive symptoms among women with no history of depression.

Menopausal symptoms themselves are also predictors of depression. In this study hot flashes, night sweats, sleep disturbance and sexual disturbance were significantly associated with depression. Other studies have found that women who reported vasomotor and other physical symptoms had elevated rates of depression. ${ }^{20,13,21}$ In another study, peri-menopausal women with vasomotor symptoms were 4.39 times more likely to be depressed than those without vasomotor symptoms (95\% CI, 1.40-13.83).22 Among Chinese women aged 45-59 years also, hot flashes and sweating were found to be risk factors associated with depression. ${ }^{23}$

CONCLUSION: Though the depressive symptoms are higher among post menopausal women compared to women who did not attained menopause, as such clinical depression is not found to be significantly increased. The vasomotor symptoms (hot flashes/night sweats), had a significant association with depression. Screening for depression in women during menopausal years will be helpful to diagnose and treat major depressive illness earlier.

\section{REFERENCES:}




\section{ORIGINAL ARTICLE}

1. Freeman EW, Sammel MD, Lin H, et al. Symptoms associated with menopausal transition and reproductive hormones in midlife women. Obstet Gynecol. 2007;110:230-240. [PubMed]

2. Freeman EW, Sammel MD, Liu L, Gracia CR, Nelson DB, Hollander L. Hormones and menopausal status as predictors of depression in women in transition to menopause. Arch Gen Psychiatry. 2004; 6:62-70. [PubMed]

3. Freeman EW, Sammel MD, Lin H, Nelson DB. Associations of hormones and menopausal status with depressed mood in women with no history of depression. Arch Gen Psychiatry. $2006 ; 63(4): 375-82$.

4. Cohen LS, Soares CN, Vitonis AF, Otto MW, Harlow BL. Risk for new onset of depression during the menopausal transition: the Harvard study of moods and cycles. Arch Gen Psychiatry. 2006; 63:385-390. [PubMed]

5. Hunter MS. Mental changes: are they due to the menopause? In: Birkhauser MH, RozenbaumH, eds. Menopause: European consensus development conference. Paris: ESKA Editions, 1996.

6. Myra S Hunter. Depression and the menopause. BMJ 1996; 313: 1217-18

7. Karen A. Matthews et al. Influences of Natural Menopause on Psychological Characteristics and Symptoms of Middle-Aged Healthy Women. Journal of Consulting and Clinical Psychology. 1990; 58( 3): 345-351

8. Jeanne Leventhal Alexander, Lorraine Dennerstein, Nancy Fugate Woods, Bruce S McEwen, Uriel Halbreich, Krista Kotz and Gregg Richardson. Role of stressful life events andmenopausal stage in wellbeing and health. Expert Rev. Neurotherapeutics2007; 7(11): S93-113

9. Avis NE, Brambilla D, McKinlay SM, Vass K. A longitudinal analysis of the association between menopause and depression. Results from the Massachusetts Women's Health Study. Ann. Epidemiol 199;: 4(3):214-220.

10. Woods Fugate N, Smith-DiJulio K, Percival D. et al. Depressed mood during the menopausal transition and early postmenopause: observations from the Seattle Midlife Women's Health Study. Menopause. 2008 ; 15(2):223-232.

11. Ellen W. Freeman, PhD, Mary D Sammel, ScD, and Hui Lin, MSTemporal associations of hot flashes and depression in the transition to menopause. Menopause. 2009; 16(4): 728-734.

12. Beck AT, and Steer RA, Manual for the Beck Depression Inventory, San Antonio: Psychological Corporation, 1993

13. Beck, A. T., Brown, G., \& Steer, R. A. (1996). Beck Depression Inventory II manual. San Antonio, TX: The Psychological Corporation

14. Greene JG. Constructing a standard climacteric scale Maturitas $1998 ; 29(1): 25-31$

15. Greene JG. Constructing a standard climacteric scale. Maturitas 2008 ; 61(1-2): $78-84$

16. N. Sa`gsöz, Ö. O`guztürk, M. Bayram, M. Kamacl. Anxiety and depression before and after the menopause. Archives of Gynecology and Obstetrics. 2001; 264( 4): 199-202

17. Tangen T, Mykletun A. Depression and anxiety through the climacteric period: an epidemiological study (HUNT-II). J. Psychosom Obstet Gynaecol. 2008;29(2):125-31

18. Freeman EW. Associations of depression with the transition to menopause Menopause. 2010 ;17(4):823-7. 


\section{ORIGINAL ARTICLE}

19. Cohen LS, Soares CN, Vitonis AF, Otto MW, Harlow BL Risk for new onset of depression during the menopausal transition: the Harvard study of moods and cycles. Arch Gen Psychiatry. $2006 ; 63(4): 385-90$.

20. Anita H. Clayton, Philip T. Ninan, Depression or Menopause? Presentation and Management of Major Depressive Disorder in Perimenopausal and Postmenopausal Women. Prim Care Companion J Clin Psychiatry. 2010; 12(1): PCC.08r00747. doi: 10.4088/PCC.08r00747blu

21. Gallicchio L; Schilling C; Miller SR; Zacur H; Flaws JA. Correlates of depressive symptoms among women undergoing the menopausal transition. J Psychosom Res 2007; 63(3):263-8

22. Ioffe H, Hall JE, Soares CN, Hennen I, Reilly CI, Carlson K, Cohen LS. Vasomotor symptoms are associated with depression in perimenopausal women seeking primary care. Menopause. 2002; 9(6):392-8.

23. Li Y, Yu Q, Ma L, Sun Z, Yang X. Prevalence of depression and anxiety symptoms and their influence factors during menopausal transition and postmenopause in Beijing city. Maturitas. 2008; 61(3):238-42. 